\title{
Presentación del Decano
}

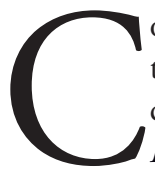

on gran satisfacción presentamos hoy la edición No 19 de nuestra revista Perfiles de Ingeniería, conscientes de que los logros que día a día obtenemos gracias a la acción de docentes e investigadores merecen ser reconocidos, pues contribuyen a la producción académica de nuestra Universidad. Directivos, docentes, científicos, ingenieros de las más diversas ramas, así como profesionales de diferentes instituciones, egresados y alumnos

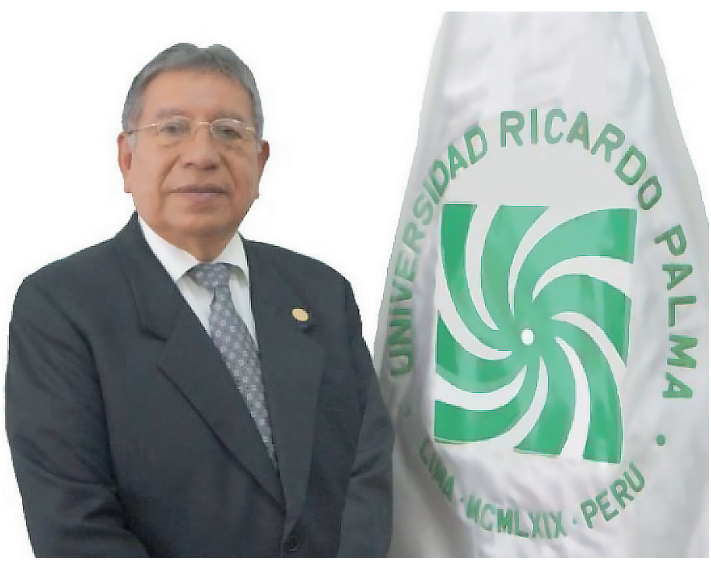
podrán encontrar en esta publicación el espacio para la actualización de sus conocimientos, y la expresión de sus conceptos en torno al contenido de la revista.

La revista Perfiles de Ingeniería nació con la finalidad conectar diversas disciplinas científicas y tecnológicas de las carreras que ofrece la Facultad de Ingeniería de la Universidad Ricardo Palma. La nuestra es una visión multidisciplinaria del mundo de la ciencia y tecnología actuales. En ese marco, nuestra facultad ha producido hasta el momento una gran cantidad de artículos en las diversas ediciones de la revista, varios de los cuales han repercutido en gran medida en la sociedad.

Los artículos publicados en esta edición representan la reciente producción académica de las carreras profesionales que ofrece nuestra facultad. Un primer y fundamental rasgo que deseamos destacar de la revista es su claro y marcado carácter participativo, que fomenta la creatividad, y busca nuevas ideas y elementos de reflexión o desarrollo en el campo de la ingeniería, las mismas que deben contribuir a solucionar los problemas que enfrenta el país.

Las diferentes secciones de la presente edición brindan una gran variedad de información correspondiente a las cinco carreras profesionales de nuestra facultad, lo que permitirá a los lectores tener una idea clara de las actividades realizadas por nuestro personal de investigación. La revista ha venido preparándose para afrontar la era del conocimiento con el propósito de convertirse en protagonista. Por esa razón, contribuye también a la consolidación de los equipos de investigación a partir de grupos de excelencia y de la formación investigativa de estudiantes. Además fomenta y desarrolla alianzas estratégicas con reconocidos grupos externos, tanto nacionales como internacionales.

En esta publicación se refleja el trabajo serio y de gran dedicación de la comunidad académica de la Facultad de Ingeniería y, asimismo, se muestra el compromiso cada vez mayor de nuestra universidad con el conocimiento y con la sociedad. El trabajo interdisciplinario es una tarea que debe ser 
abordada con creciente énfasis en la formación académica y estamos seguros de que se seguirá enriqueciendo en las próximas ediciones de nuestra revista.

Finalmente, deseo destacar la activa participación de los docentes investigadores de nuestra facultad, cuyos artículos fueron aprobados para esta edición. Soy testigo del empeño, talento y entusiasmo con los que el comité editorial, en coordinación permanente con los diferentes autores, emprendieron sus respectivos trabajos, de la autenticidad de sus producciones y de su voluntad en la búsqueda permanente de la verdad. Por tales motivos, expreso mi reconocimiento al personal docente y administrativo que participó en este nuevo logro, que sin dudas permitirá alcanzar cada vez mayores estándares de calidad académica.

MSc. Ing. Carlos Sebastián Calvo

Decano

Facultad de Ingeniería 